\title{
ORIGINAL ARTICLE \\ Vegetable but not animal protein intake is associated to a better physical performance: a study on a general population sample of adults
}

\author{
Diana Gazzani'*, Francesco Zamboni², Francesco Spelta², Pietro Ferrari², Veronica \\ Mattioli3 ${ }^{3}$ Lucia Cazzoletti ${ }^{3}$, Elisabetta Zanolin³ ${ }^{3}$ Stefano Tardivo' and Marcello Ferrari \\ 'Department of Diagnostics and Public Health, Unit of Hygiene and Preventive, Environmental and Occupational \\ Medicine, University of Verona, Verona, Italy; ${ }^{2}$ Department of Medicine, Unit of Respiratory Disease and Sports \\ Medicine, University of Verona, Italy; ${ }^{3}$ Department of Diagnostics and Public Health, Unit of Epidemiology and \\ Statistical Medicine, University of Verona, Italy
}

\section{Popular scientific summary}

- Few studies have been conducted on the separate effect of animal and vegetable protein on physical performance.

- Analysing this relationship, we found an unexpected result, suggesting that a higher vegetable protein intake is associated with a better performance at 6-min walking test.

- Whether this result is related to the high protein intake itself or may be a consequence of the other properties of plant-based foods deserves further investigation.

Abstract

Background: The research was conducted in the frame of a population-based, case control study, called Genes Environment Interaction in Respiratory Disease.

Objective: To assess the association between protein intake and physical performance in a general population sample.

Design: Researchers investigated the association between the participants' dietary information and their physical performance using the 6-min walking test and the distance walked in metres (6MWD) as main outcome measure. Information on dietary intake was collected using the validated European Investigation into Cancer and Nutrition food frequency questionnaires (FFQs). Then, daily intake of energy and macronutrients was estimated by means of the NAF software (nutritional analysis of FFQ). Linear regression models were used to evaluate the associations between vegetable, animal and total protein intakes and the 6MWD. The models were adjusted for socio-demographic features, total fats and available carbohydrate intakes.

Results: The participants were 223 subjects (57\% females) aged between 23 and 68 years. Their mean vegetable and animal proteins intake for gram $/ \mathrm{kg}$ of body weight/day were, respectively, 0.4 and 0.7 . After adjusting for all the potential confounders, there was a significant increase of $20.0(95 \% \mathrm{CI} 0.8 ; 39.2) \mathrm{m}$ in the distance walked for an increase in $10 \mathrm{~g} /$ day of vegetable proteins and non-significant variations of $-1.8(95 \% \mathrm{CI}-9.3 ; 5.7) \mathrm{m}$ for an increase in $10 \mathrm{~g} /$ day of animal proteins and of $0.5(95 \% \mathrm{CI}-6.8 ; 7.7)$ for an increase in $10 \mathrm{~g} /$ day of total proteins. Discussion and conclusions: Our result suggests a positive role of vegetable proteins on physical performance. Whether this result is related to the high protein intake itself or may be a consequence of the other properties of plant-based foods deserves further investigation.

Keywords: six minute walking test; nutrition; diet; exercise; proteins

Received: 9 January 2019; Revised: 3 June 2019; Accepted: 24 June 2019; Published: 19 September 2019

A poor physical performance tested by objective measures of physical capacity seems to play a significant role in predicting an increased risk of mortality and morbidity in the general elderly adult population (1-3). In the last decades, the accumulation of evidence has provided new findings on the impact of 
the nutritional status on the health and functional capacity in the general population $(4,5)$. It is well known that an adequate intake of quality protein is a key factor for building, preserving muscle mass and maintaining physical functions. Currently, the recommended protein intake is $0.8 \mathrm{~g} / \mathrm{kg}$ body weight/day (bw/day) for adults (6), even though this amount is a rough estimate, based on the minimal protein intake necessary to maintain the nitrogen balance in adults. It has recently been proposed that the protein intake of $1.0-1.2 \mathrm{~g} / \mathrm{kg}$ bw/day is likely to be the amount that is required to ameliorate muscle health without damaging the renal function $(4,7)$. As regards the quality of proteins, it is a common opinion to favour those of animal origin since a greater proportion of daily protein intake derived from animal- versus plant-based sources seems to be associated with better muscle maintenance in older adults (8). Furthermore, animal proteins are more easily available and have a higher level of essential amino acids, which increases protein synthesis and anabolism $(9,10)$. Several previous investigations (11-15) have been conducted on the association between dietary protein intake and physical performance. Data from these studies generally support the effect of animal protein on preserving muscle mass and improving muscle strength in older adults $(9,16,17)$. On the contrary, few studies have examined the association of a dietary protein intake, in terms of both quantity and quality, with physical performance measures in middle-aged adults (i.e. aged between 40 and 65 years). In view of the scarcity of evidence on this topic, the present study aimed at investigating the possible relationship between total animal and vegetable protein intake and the distance walked in $6 \mathrm{~min}$ in a cohort of subjects from the general population.

\section{Methods}

\section{Study design}

The Genes Environment Interaction in Respiratory Diseases (GEIRD) project is a multi-case-control study on respiratory diseases, carried out between 2007 and 2010 in Italy. The sample was randomly selected from the general population in six centres (Pavia, Sassari, Turin, Ancona, Terni and Verona) by using the local health authority records. The GEIRD project's design is described in detail elsewhere (18). In brief, cases of chronic bronchitis, chronic obstructive pulmonary disease, asthma or rhinitis and controls without respiratory symptoms were identified through a two-step design (postal screening, clinical interview). During the clinical interview, subjects performed the 6MWT and filled in a food frequency questionnaire (FFQ). In the present analysis, only subjects without respiratory symptoms or diseases who participated in the study in Verona, with valid information on their usual dietary intake and on the execution of the
6MWT, were considered ( $n=223$ ). Written informed consent was obtained from all participants.

\section{Dietary information}

Information on the subjects' usual dietary intake was collected by using the Italian version of the validated European Investigation into Cancer and Nutrition (EPIC) FFQ (19). To ensure the quality of participants' dietary reporting, participants who filled less than $70 \%$ of the total number of questions, as well as the subjects with an extremely low caloric intake level and those on top and bottom $0.5 \%$ of the distribution of Energy Intake/Basal Metabolism Ratio (EI/BMR), were excluded from the study. Then, daily intake of energy and macronutrients was estimated by means of the NAF software (nutritional analysis of FFQs, National Cancer Institute, Milan, Italy) (20), and the information on nutrients for specific foods consumed in Italy was obtained from the food composition database for epidemiological studies in Italy (21).

\section{MWT}

The 6MWT was performed following the American Thoracic Society guidelines (22). Before performing the test, subjects were checked for contraindications. Subjects were asked to walk as fast as they could without running in a 25-m-long hallway, for $6 \mathrm{~min}$. The test results were expressed as the distance walked (6MWD) in metres. Out of 255 controls with available information on their nutritional status, $32(12.5 \%)$ did not perform the 6-min walking test (6-MWT), because of clinical contraindications, including heart attack occurred in the previous 3 months, current drug treatment for epilepsy, a heart rate more than 120 beats per minute and a systolic blood pressure over $180 \mathrm{mmHg}$ or a diastolic blood pressure over $100 \mathrm{mmHg}$.

\section{Exposures and potential confounders}

Vegetable and animal protein intakes (g/day) were considered as determinants. The following covariates were considered as potential confounders: gender, age, height, weight, smoking habits (never smoker, past smoker, i.e. not smoking in the last month or current smoker), comorbidity, self-reported intensity of physical exercise, total fats and available carbohydrates (i.e. the sum of monosaccharides, disaccharides, dextrins, starch and glycogen expressed in monosaccharides). The distribution of the total energy intake in $\mathrm{kJ} /$ day (or in $\mathrm{kcal} /$ day) was also calculated. According to the participants' questionnaire answers, the comorbidity status was defined by the presence of self-reported medical diagnosis of at least one of the following diseases: arterial hypertension, diabetes, cardiovascular comorbidity (at least one of lifetime heart attack, ictus, angina pectoris, arrhythmia, heart or aorta surgery) and cancer. Intensity of exercise performed during a week 
was classified into three levels and estimated by asking participants how often, and for how many hours weekly they were exercising so as to have a feeling of shortness of breath and to sweat.

\section{Statistics}

Subject characteristics were summarised as percentages or means (SD). A two sample $t$-test on the equality of means was performed to investigate the difference in physical performance (6MWD) between subjects ingesting more

Table 1. Socio-demographic characteristics of participants $(N=223)$

\begin{tabular}{lc}
\hline & Participants $(n=223)^{*}$ \\
\hline Age at the clinical visit, years & $45.8 ; 9.6$ \\
Males & $43.0(96)$ \\
Females & $57.0(127)$ \\
BMI, kg/m & $24.4 ; 4.0$ \\
Weight, kg & $70.6 ; 14.8$ \\
Height, cm & $169.6 ; 9.4$ \\
Non smoker & $58.1(129)$ \\
Ex-smoker & $28.8(64)$ \\
Current smoker & $13.1(29)$ \\
Heavy physical activity & $7.6(17)$ \\
Moderate physical activity & $44.0(98)$ \\
Light physical activity & $48.4(108)$ \\
Presence of comorbidity & $24.8(55)$ \\
Absence of comorbidity & $75.2(167)$ \\
\hline
\end{tabular}

\$Subject characteristics were summarised as percentages (number of observations) or means (SD) related to qualitative and quantitative variables, respectively. *There were missing values on smoking habits (one missing value) and comorbidity (one missing value), so the percentages were calculated considering the total number of subjects after excluding the missing data. or less than $0.8 \mathrm{~g}$ protein per $\mathrm{kg}$ of body mass-daily, which is the recommended daily allowance (RDA) for proteins (23). Models considering the 6MWD as the dependent variable were fitted using a simple linear regression for the nutrient intakes of interest. Then, multiple linear regression models were fitted to the data, with each nutrient intake as the independent variable, adjusting for a first set of potential confounders (gender, age, height, weight, smoking habits, comorbidities and the self-reported intensity of physical training). Another model was fitted considering, in addition to the first set of confounders, also animal proteins, vegetables proteins, total fats and available carbohydrates. Lastly, a multiple regression model similar to the previous one was fitted taking into account the total proteins (expressed as g/day) instead of vegetable and animal proteins separately. All statistical analyses were performed using the software Stata, version 13.0 (www.stata.com).

\section{Results}

The socio-demographic characteristics of the 223 participants are shown in Table 1. Their mean age at the clinical visit was 45.8 years $(\mathrm{SD}=9.6$ years; range $=$ 22.8-68.4 years). Most participants were women (57.0\%), had a normal mean value of BMI $(24.4 \mathrm{~kg}$; range = $16.9-39.8 \mathrm{~kg} / \mathrm{m})$, were non-smoker $(58.1 \%)$ and reported a light intensity of physical training $(48.4 \%)$ and the absence of comotbidities (75.2\%). The mean value of weight and height were 70.6 (range $=41-110) \mathrm{kg}$ and $169.6($ range $=147-192) \mathrm{cm}$, respectively $($ Table 1$)$. Their dietary intake is shown in Table 2. The median total energy intake was $7,924.5 \mathrm{~kJ} /$ day $(=1,894 \mathrm{kcal} /$ day $)$. The subjects reported daily median intakes of $48.2 \mathrm{~g} /$ day for animal proteins (i.e. $0.7 \mathrm{~g} / \mathrm{kg}$ bw/day) and $24.3 \mathrm{~g} /$ day for

Table 2. Nutritional intake estimates of participants $(N=223)$

\begin{tabular}{lccc}
\hline Nutritional dietary intake & Median & First quartile; third quartile & Range \\
\hline Vegetable protein - g/day & 24.3 & $18.3 ; 31.2$ & $8.2-95.7$ \\
Animal protein - g/day & 48.2 & $38.1 ; 63.7$ & $9.5-122.5$ \\
Total protein - g/day & 73.3 & $58.5 ; 93.6$ & $22.7-180.6$ \\
Vegetable protein-g/kg/day & 0.4 & $0.3 ; 0.5$ & $0.1-1.3$ \\
Animal protein-g/kg/day & 0.7 & $0.5 ; 1.0$ & $0.1-2.2$ \\
Total proteins-g/kg/day & 1.1 & $0.8 ; 1.4$ & $0.3-2.7$ \\
Available carbohydrates - g/day & 235.6 & $174.4 ; 308.7$ & $73.1-748.9$ \\
Total fats -g/day & 74.8 & $60.6 ; 95.6$ & $20.6-169.8$ \\
Total energy intake - kJ/day & $7,926.2$ & $62,960.8 ; 103,989.1$ & $2,985.3-19,491.2$ \\
[Total energy intake - kcal/day] & {$[1,894.4]$} & {$[1,504.8 ; 2,485.4]$} & $1713.5-4,658.5]$ \\
Total proteins- energy \% & 15.5 & $14.1 ; 17.3$ & $9.9-26.3$ \\
Vegetable protein-energy \% & 5.1 & $4.5 ; 5.8$ & $3.0-8.6$ \\
Animal protein-energy $\%$ & 10.0 & $8.5 ; 12.3$ & $3.9-22.7$ \\
Available carbohydrates - energy\% & 49.1 & $28.4-71.0$ \\
Total fats-energy \% & 35.3 & $31.2 ; 54.3$ & $22.5-53.0$ \\
\hline
\end{tabular}


Table 3. Simple and multiple linear regression coefficients (with 95\% CIS) for regression of $6 \mathrm{MWD}(\mathrm{M})$ against nutrient intakes for an increase of $10 \mathrm{~g} /$ day

\begin{tabular}{|c|c|c|c|}
\hline Nutritional dietary intake $-10 \mathrm{~g} /$ day & $\begin{array}{c}b \text {-Coefficient } \\
\text { (simple linear regression) }\end{array}$ & $\begin{array}{l}\text { Adjusted b-coefficient }\left(^{*}\right) \text { (multiple } \\
\text { linear regression) }\end{array}$ & $\begin{array}{l}\text { Adjusted b-coefficient }(* *) \\
\text { (multiple linear regression) }\end{array}$ \\
\hline Animal protein & $-0.3(-4.7 ; 4.0)$ & $-1.4(-5.5 ; 2.8)$ & $-1.8(-9.3 ; 5.7)$ \\
\hline Vegetable protein & $13.2(5.4 ; 21.0)$ & $9.5(1.7 ; 17.3)$ & $20.0(0.8 ; 39.2)$ \\
\hline Total fats & I.5 (-1.9;4.9) & $0.1(-3.2 ; 3.3)$ & $-1.4(-8.4 ; 5.6)$ \\
\hline Available carbohydrates & $1.3(0.4 ; 2.3)$ & $0.8(-0.1 ; 1.7)$ & $-0.9(-3.3 ; 1.5)$ \\
\hline
\end{tabular}

*b-Coefficient is adjusted for the following covariates: gender, age, height, weight, smoking habits, comorbidities and the self-reported intensity of physical training; **b-Coefficient is adjusted for the following covariates: gender, age, height, weight, smoking habits, comorbidities, the self-reported intensity of physical training, vegetable protein ( $g /$ day), animal protein $(\mathrm{g} /$ day), available carbohydrates $(\mathrm{g} /$ day) and total fats $(\mathrm{g} /$ day). Regression coefficients that are significantly different from 0 are reported in bold.

vegetable proteins (i.e. $0.4 \mathrm{~g} / \mathrm{kg}$ bw/day). Table 2 reports daily dietary information reported as percentage of total energy intake.

The majority of the participants $(78.9 \%)$ reported a protein intake that was more than $0.8 \mathrm{~g}$ protein per $\mathrm{kg}$ of body mass-daily. The median 6MWD value was $599.4 \mathrm{~m}$ $(\mathrm{SD}=70.0)$. There was not a significant difference in the 6MWD between subjects ingesting more or less than $0.8 \mathrm{~g}$ protein per $\mathrm{kg}$ of body mass-daily (599.8 and $598.1 \mathrm{~m}$, respectively, $P=0.89$ ). When considering the simple linear regression, there was a significant increase of $13.2(95 \% \mathrm{CI}: 5.4 ; 21.0) \mathrm{m}(P<0.001)$ for $10 \mathrm{~g} /$ day increase in the vegetable protein intake (Table 3 ), and no apparent variation of the 6MWD $(-0.3 ; 95 \% \mathrm{CI}:-4.7$; $4.0 \mathrm{~m}, P=0.881)$ for $10 \mathrm{~g} /$ day increase in the animal protein intake (Table 3). When adjusting for the first set of confounders (gender, age, height, weight, smoking habits, comorbidities and intensity of physical training) and when also adjusting for all the other nutrients (i.e. animal proteins, total fats and available carbohydrates), the positive association between the vegetable protein intake and the 6MWD was confirmed. When considering the latter multivariable regression model, the predicted increase in the $6 \mathrm{MWD}$ was $20.0(95 \% \mathrm{CI}: 0.8 ; 39.2 ; P=0.041) \mathrm{m}$ for $10 \mathrm{~g} /$ day increase in the vegetable protein intake (Table 3 , Fig. 1, upper panel). Total fats ( $b$ coefficient for $10 \mathrm{~g}$ intake increase $=-1.4 ; P=0.69)$ as well as available carbohydrates $(b$ coefficient for $10 \mathrm{~g}$ intake increase $=-0.9$; $P=0.44$ ) and animal proteins ( $b$ coefficient for $10 \mathrm{~g}$ intake increase $=-1.8 ; P=0.64)$ were not associated with the 6MWD (Table 3, last column; Fig. 1, lower panel). Lastly, another multiple regression model was fitted to the data, taking into account the total proteins, instead of vegetable and animal proteins separately, and adjusting for all the above-mentioned confounders, including total fats and available carbohydrates. This model showed that the total protein intake $(b$ coefficient for $10 \mathrm{~g}$ intake increase $=0.5$; $95 \% \mathrm{CI}-6.8 ; 7.7)$ was not associated with the $6 \mathrm{MWD}$.
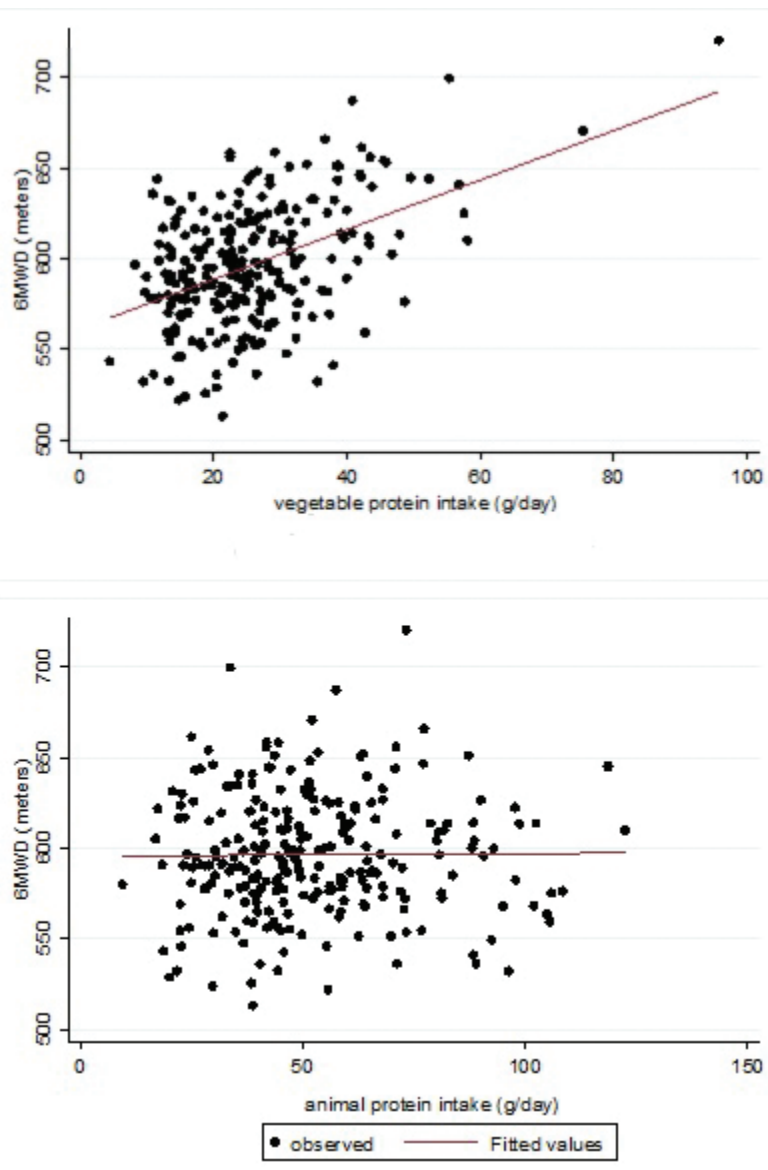

Fig. 1. Vegetable protein intake (g/day) or animal protein intake (g/day) and 6MWD (metres). The lines represent the fitted value of the multiple linear regressions where the dependent variable is 6MWD and the independent variable is the vegetable protein intake (upper panel) and the animal protein intake (lower panel). The two models are adjusted for the following covariates: gender, age, height, weight, smoking habits, comorbidities, the intensity of physical training, vegetable protein ( $\mathrm{g} /$ day), animal protein (g/day), available carbohydrates (g/day) and total fats (g/day). 


\section{Discussion}

Our main result was the finding of a direct relationship between the vegetable protein intake and the distance walked in the 6MWT. It is noteworthy to mention that the association persisted after adjusting for several possible confounders. On the contrary, no significant association was found for animal and total protein intakes. Several previous studies (11-14) have been conducted on the association between dietary protein intake and physical performance. Isanejad et al. (13), studying women aged 65-71 years belonging to the Osteoporosis Risk Factor and Prevention Fracture Prevention Study, demonstrated that subjects with a higher protein intake $(\geq 1.2 \mathrm{~g} / \mathrm{kg})$ had a significantly better physical function and muscle strength compared with those with moderate and lower intakes. Gregorio et al. (11) demonstrated that upper and lower extremity function was impaired in older women consuming a low protein diet (below the RDA for protein defined as less than $0.8 \mathrm{~g}$ protein $/ \mathrm{kg}$ ) compared to those with a higher protein intake, and Radavelli-Bagatini et al. found that dairy protein intake improved physical function in older women (15). Finally, an insufficient consumption of protein has been associated with impairment of physical function and of quality of life in older adults with depression (12). Differently from previous studies (11-13), we found no association between exercise capacity and total protein intake, and we could not demonstrate a different physical performance between subjects ingesting more or less than $0.8 \mathrm{~g}$ protein per $\mathrm{kg}$ of body mass-daily. Several reasons may justify the contrasting results. The total protein intake of our sample (median value of $1.1 \mathrm{~g} / \mathrm{kg} \mathrm{bw} /$ day) was comparable with the intake of previous studies in Caucasians, ranging from 0.8 to $1.2 \mathrm{~g} / \mathrm{kg}(16,24)$. Thus, other factors may account for the discrepant results, as explained in the following. The difference in the results may be attributed to the fact that previous studies were generally carried out on elderly subjects (12-15), who have different skeletal muscle characteristics from those of middle-aged subjects (8). The different methods used to evaluate physical performance, directed to the measurement of strength and balance in previous studies (11-15), and to the evaluation of aerobic capacity in the present one, may also justify the contrasting results. Our data indicate that a higher vegetable protein intake is associated with a better performance at 6MWT. This result was unexpected since animal protein seems to have a higher essential amino acid content and a better protein availability, a characteristic that might ameliorate muscle protein synthesis and anabolism $(7,25)$. Few studies have been conducted on the separate effect of animal and vegetable protein on physical performance. Houston et al. found that the intake of animal but not vegetable protein was associated with the preservation of lean body mass in a 3-year follow-up study in older adults (16). These results were consistent with those obtained in a cross-sectional study by Lord et al. (26). In addition, the finding that an omnivorous diet increases lean body mass, while lacto-ovo-vegetarian diet results in a loss, though modest, of lean mass in males participating in a programme of resistance training, seems to support an overall better effect of animal proteins on muscle (10). After studying an older group of Chinese community-dwelling people for 4 years, Chan et al. found that a higher protein intake deriving from vegetables, but not from animal source, was associated with the preservation of muscle mass (27). Similarly, in a longitudinal cohort study in Japan, Kojima et al. showed that the age-related decline in muscle strength in women was lower in those who frequently eat soy products or green and yellow vegetables (28). The reasons for our unexpected results are not clear. The association between plant-based proteins and the 6-min walking distance may not be due to the effect of these macro-nutrients on muscle, but it could be related to other components of vegetable foods, such as antioxidants, potentially affecting muscle mass and strength (29). This hypothesis is speculative and warrants further investigation. The present study differs from the previous ones inasmuch the physical performance was evaluated by using the 6MWT, which is influenced not only by muscle strength, but also by cardiovascular and respiratory function (30). While animal proteins seem to improve muscle protein synthesis more than plant proteins (31), a vegetable protein-dietary intake is associated with beneficial cardiovascular effects both in healthy subjects (32) and in patients (33). Particularly, vegetarian dietary practices have been associated with several health benefits, among which are lower risks of dyslipidaemia, hypertension, obesity (34-37) and of chronic diseases in general (32, 38-45). Since many factors related to cardiovascular diseases may negatively affect physical performance (46), it is possible to speculate that the positive association between vegetable protein intake and 6MWD is mediated by a general health benefit rather than through a direct effect on muscle. In other words, a diet rich in vegetable products may be part of a healthy lifestyle and as a consequence of a better physical performance.

The increase in the distance walked by the intake of $10 \mathrm{~g} /$ day of vegetable proteins is $20 \mathrm{~m}$ in the adjusted model. As expected, this increase is quite small; however, there are no indications on a 6MWD variation describing a meaningful change of performance. Moreover, it is interesting to observe that we found an increase in the distance walked by $10 \mathrm{~g} /$ day of vegetable proteins $(20 \mathrm{~m})$ comparable to the difference associated with gender (adjusted difference in males with respect to females is $25.3 \mathrm{~m}$ ). Therefore, we suppose that the increase observed is not negligible. 
Our study has some limitations. Dietary assessment by FFQ is subject to the recall bias, so that the measurement error may distort the association between nutrient intakes and outcome measures. On the other hand, the FFQ provided visual aids for the estimation of portions, and this could have been useful to improve the accuracy of the reported information. Moreover, the diet was assessed at a single point in time, a fact that reflects recent rather than long-term exposure; however, there is evidence that adults maintain relatively stable long-term dietary habits (47). We also acknowledge that the study was performed on subjects without respiratory diseases, so the results could not be generalised.

The strengths and originality of this study are that we evaluated a representative sample of middle-aged subjects from the general population and we considered the vegetable and animal protein intake separately, using validated food frequency questionnaires with a careful dietary assessment.

\section{Conclusions}

In conclusion, our population-based study did not show any association between total and animal protein intake and the distance walked in $6 \mathrm{~min}$. On the contrary, a higher protein intake from a vegetable source resulted in a better physical performance. Whether this result is related to the high vegetable protein intake itself or is a consequence of the antioxidant property of plant-based foods or of some beneficial effect associated with a plant-rich dietary pattern, deserves further investigation. However, recommending higher intakes of vegetable protein might be a useful measure for ameliorating physical performance in the general population.

\section{Acknowledgements}

The GEIRD project was funded by the Cariverona Foundation, the Italian Ministry of Health, Chiesi Farmaceutici and the Italian Medicines Agency (AIFA). The funders had no role in the design, in the collection, analysis and interpretation of the data; in the writing of the manuscript; and in the decision to submit the manuscript for publication.

\section{Financial support}

This research received no specific grant from any funding agency, commercial or not-for-profit sectors.

\section{Conflict of interest and funding}

The authors declare no potential conflicts of interest.

\section{Ethical standards disclosure}

This study was conducted according to the guidelines laid down in the Declaration of Helsinki and all procedures involving human subjects were approved by the Comitato Etico per la Sperimentazione - Azienda Ospedaliera di Verona. Written informed consent was obtained from all subjects.

\section{References}

1. Cooper R, Kuh D, Hardy R; Mortality Review Group; FALCon and HALCyon Study Teams. Objectively measured physical capability levels and mortality: systematic review and metaanalysis. BMJ 2010; 341: c4467. doi: 10.1136/bmj.c4467.

2. Cooper R, Kuh D, Cooper C, Gale CR, Lawlor DA, Matthews F, et al. Objective measures of physical capability and subsequent health: a systematic review. Age Ageing 2011; 40(1): 14-23. doi: 10.1093/ageing/afq117.

3. Cooper R, Muniz-Terrera G, Kuh D. Associations of behavioural risk factors and health status with changes in physical capability over 10 years of follow-up: the MRC National Survey of Health and Development. BMJ Open 2016; 6(4): e009962. doi: 10.1136/ bmjopen-2015-009962.

4. Mithal A, Bonjour J, Dawson-Hughes B; IOF CSA Nutrition Working Group. Impact of nutrition on muscle mass, strength, and performance in older adults: response to Scott and Jones. Osteoporos Int 2014; 25(2): 793. doi: 10.1007/s00198-013-2490-7.

5. Chaput JP, Lord C, Cloutier M, Aubertin Leheudre M, Goulet $\mathrm{ED}$, Rousseau S, et al. Relationship between antioxidant intakes and class I sarcopenia in elderly men and women. J Nutr Health Aging 2007; 11(4): 363-9.

6. Volpi E, Campbell WW, Dwyer JT, Johnson MA, Jensen GL, Morley JE, et al. Is the optimal level of protein intake for older adults greater than the recommended dietary allowance? J Gerontol A Biol Sci Med Sci 2013; 68(6): 677-81. doi: 10.1093/gerona/gls229.

7. Wolfe RR, Miller SL, Miller KB. Optimal protein intake in the elderly. Clin Nutr 2008; 27(5): 675-84. doi: 10.1016/j. clnu.2008.06.008.

8. Burd NA, Gorissen SH, van Loon LJ. Anabolic resistance of muscle protein synthesis with aging. Exerc Sport Sci Rev 2013; 41(3): 169-73. doi: 10.1097/JES.0b013e318292f3d5

9. Pannemans DL, Wagenmakers AJ, Westerterp KR, Schaafsma G, Halliday D. Effect of protein source and quantity on protein metabolism in elderly women. Am J Clin Nutr 1998; 68(6): 1228-35. doi: 10.1093/ajcn/68.6.1228

10. Campbell WW, Barton ML Jr, Cyr-Campbell D, Davey SL, Beard JL, Parise G, et al. Effects of an omnivorous diet compared with a lactoovovegetarian diet on resistance-training-induced changes in body composition and skeletal muscle in older men. Am J Clin Nutr 1999; 70(6): 1032-9. doi: 10.1093/ajcn/70.6.1032

11. Gregorio L, Brindisi J, Kleppinger A, Sullivan R, Mangano KM, Bihuniak JD, et al. Adequate dietary protein is associated with better physical performance among post-menopausal women 60-90 years. J Nutr Health Aging 2014; 18(2): 155-60. doi: 10.1007/s12603-013-0391-2.

12. Guligowska A, Pigłowska M, Fife E, Kostka J, Sołtysik BK, Kroc $€$, et al. Inappropriate nutrients intake is associated with lower functional status and inferior quality of life in older adults with depression. Clin Interv Aging 2016; 11: 1505-1517. doi: 10.2147/CIA.S114669

13. Isanejad M, Mursu J, Sirola J, Kröger H, Rikkonen T, Tuppurainen $\mathrm{M}$, et al. Dietary protein intake is associated with better physical function and muscle strength among elderly women. Br J Nutr 2016; 115(7): 1281-91. doi: 10.1017/S000711451600012X.

14. Martin H, Aihie Sayer A, Jameson K, Syddall H, Dennison EM, Cooper $\mathrm{C}$, et al. Does diet influence physical performance in community-dwelling older people? Findings from the Hertfordshire 
Cohort Study. Age Ageing 2011; 40(2): 181-6. doi: 10.1093/ ageing/afq175.

15. Radavelli-Bagatini S, Zhu K, Lewis JR, Dhaliwal SS, Prince RL. Association of dairy intake with body composition and physical function in older community-dwelling women. J Acad Nutr Diet 2013; 113(12): 1669-74. doi: 10.1016/j.jand.2013.05.019.

16. Houston DK, Nicklas BJ, Ding J, Harris TB, Tylavsky FA, Newman AB, et al. Dietary protein intake is associated with lean mass change in older, community-dwelling adults: the Health, Aging, and Body Composition (Health ABC) Study. Am J Clin Nutr 2008; 87(1): 150-5. doi: 10.1093/ajcn/87.1.150

17. Scott D, Blizzard L, Fell J, Giles G, Jones G. Associations between dietary nutrient intake and muscle mass and strength in community-dwelling older adults: the Tasmanian Older Adult Cohort Study. J Am Geriatr Soc 2010; 58(11): 2129-34. doi: 10.1111/j.1532-5415.2010.03147.x.

18. Marcon A, Girardi P, Ferrari M, Olivieri M, Accordini S, Bombieri C, et al. Mild asthma and chronic bronchitis seem to influence functional exercise capacity: a multi-case control study. Int Arch Allergy Immunol 2013; 161(2): 181-8. doi: 10.1159/000345137.

19. Pisani P, Faggiano F, Krogh V, Palli D, Vineis P, Berrino F. Relative validity and reproducibility of a food frequency dietary questionnaire for use in the Italian EPIC centres. Int J Epidemiol 1997; 26(Suppl 1): S152-60. doi: 10.1093/ije/26.suppl_1.s152

20. Pala V, Sieri S, Palli D, Salvini S, Berrino F, Bellegotti M, et al. Diet in the Italian EPIC cohorts: presentation of data and methodological issues. Tumori 2003; 89(6): 594-607.

21. Salvini S, Parpinel M, Gnagnarella P, Maisonneuve P, Turrini A. Banca Dati di Composizione degli Alimenti per Studi Epidemiologici in Italia. Milan, Italy: Istituto Europeo di Oncologia; 1998.

22. ATS Committee on Proficiency Standards for Clinical Pulmonary Function Laboratories. ATS statement: guidelines for the six-minute walk test. Am J Respir Crit Care Med 2002; 166(1): 111-17. doi: 10.1164/ajrccm.166.1.at1102

23. Rand WM, Pellett PL, Young VR. Meta-analysis of nitrogen balance studies for estimating protein requirements in healthy adults. Am J Clin Nutr 2003; 77(1): 109-27. doi: 10.1093/ajcn/77.1.109

24. Beasley JM, LaCroix AZ, Neuhouser ML, Huang Y, Tinker L, Woods N, et al. Protein intake and incident frailty in the women's health initiative observational study. J Am Geriatr Soc 2010; 58(6): 1063-71. doi: 10.1111/j.1532-5415.2010.02866.x.

25. van Vliet S, Burd NA, van Loon LJ. The skeletal muscle anabolic response to plant- versus animal-based protein consumption. J Nutr 2015; 145(9): 1981-91. doi: 10.3945/jn.114.204305.

26. Lord C, Chaput JP, Aubertin-Leheudre M, Labonté M, Dionne IJ. Dietary animal protein intake: association with muscle mass index in older women. J Nutr Health Aging 2007; 11(5): 383-7.

27. Chan R, Leung J, Woo J, Kwok T. Associations of dietary protein intake on subsequent decline in muscle mass and physical functions over four years in ambulant older Chinese people. J Nutr Health Aging 2014; 18(2): 171-7. doi: 10.1007/s12603-013-0379-y.

28. Kojima N, Kim M, Saito K, Yoshida H, Yoshida Y, Hirano H, et al. Lifestyle-related factors contributing to decline in knee extension strength among elderly women: a cross-sectional and longitudinal cohort study. PLoS One 2015; 10(7): e0132523. doi: 10.1371/journal.pone.0132523.

29. Ives SJ, Bloom S, Matias A, Morrow N, Martins N, Roh Y, et al. Effects of a combined protein and antioxidant supplement on recovery of muscle function and soreness following eccentric exercise. $\mathbf{J}$ Int Soc Sports Nutr 2017; 14: 21. doi: 10.1186/s12970-017-0179-6.

30. Joobeur S, Rouatbi S, Latiri I, Sfaxi R, Ben Saad H. Influencing factors of the 6-min walk distance in adult Arab populations: a literature review. Tunis Med 2016; 94(5): 339-348.
31. Gilbert JA, Bendsen NT, Tremblay A, Astrup A. Effect of proteins from different sources on body composition. Nutr Metab Cardiovasc Dis 2011; 21(Suppl 2): B16-31. doi: 10.1016/j. numecd.2010.12.008.

32. Hoffman JR, Falvo MJ. Protein - which is best? J Sports Sci Med 2004; 3(3): 118-30.

33. Karamali M, Kashanian M, Alaeinasab S, Asemi Z. The effect of dietary soy intake on weight loss, glycaemic control, lipid profiles and biomarkers of inflammation and oxidative stress in women with polycystic ovary syndrome: a randomised clinical trial. J Hum Nutr Diet 2018; 31(4): 533-543. doi: 10.1111/jhn.12545.

34. Appleby PN, Thorogood M, Mann JI, Key TJ. The Oxford vegetarian study: an overview. Am J Clin Nutr 1999; 70(3 Suppl): 525S-531S. doi: 10.1093/ajen/70.3.525s.

35. Melby CL, Toohey ML, Cebrick J. Blood pressure and blood lipids among vegetarian, semivegetarian, and nonvegetarian African Americans. Am J Clin Nutr 1994; 59(1): 103-9. doi: 10.1093/ajcn/59.1.103

36. Thorogood M, Carter R, Benfield L, McPherson K, Mann JI. Plasma lipids and lipoprotein cholesterol concentrations in people with different diets in Britain. Br Med J (Clin Res Ed) 1987; 295(6594): 351-3. doi: 10.1136/bmj.295.6594.351

37. Levin N, Rattan J, Gilat T. Energy intake and body weight in ovo-lacto vegetarians. J Clin Gastroenterol 1986; 8(4): 451-3.

38. Thorogood M, Mann J, Appleby P, McPherson K. Risk of death from cancer and ischaemic heart disease in meat and non-meat eaters. BMJ 1994; 308(6945): 1667-70. doi: 10.1136/ bmj.308.6945.1667

39. Fraser GE, Lindsted KD, Beeson WL. Effect of risk factor values on lifetime risk of and age at first coronary event. The adventist health study. Am J Epidemiol 1995; 142(7): 746-58. doi: 10.1093/oxfordjournals.aje.a117706

40. Burr ML, Sweetnam PM. Vegetarianism, dietary fiber, and mortality. Am J Clin Nutr 1982; 36(5): 873-7. doi: 10.1093/ ajen/36.5.873

41. Snowdon DA, Phillips RL. Does a vegetarian diet reduce the occurrence of diabetes? Am J Public Health 1985; 75(5): 507-12. doi: 10.2105/ajph.75.5.507

42. Snowdon DA, Phillips RL, Fraser GE. Meat consumption and fatal ischemic heart disease. Prev Med 1984; 13(5): 490-500.

43. Giovannucci E, Rimm EB, Stampfer MJ, Colditz GA, Ascherio A, Willett WC. Intake of fat, meat, and fiber in relation to risk of colon cancer in men. Cancer Res 1994; 54(9): 2390-7.

44. White R, Frank E. Health effects and prevalence of vegetarianism. West J Med 1994; 160(5): 465-70.

45. Hasler CM. The cardiovascular effects of soy products. J Cardiovasc Nurs 2002; 16(4): 50-63; quiz 75-6.

46. Bourahli MK, Bougrida M, Martani M, Mehdioui H, Saad HB. 6-Min walk-test data in healthy North-African subjects aged 16-40 years. Egypt J Chest Dis Tu 2016; 65(1): 349-60. doi: 10.1016/j.ejcdt.2015.08.003.

47. Macdonald HM, New SA, Reid DM. Longitudinal changes in dietary intake in Scottish women around the menopause: changes in dietary pattern result in minor changes in nutrient intake. Public Health Nutr 2005; 8(4): 409-16.

\footnotetext{
*Diana Gazzani

Department of Diagnostics and Public Health

Biological Institute, 8 Le Grazie Street

IT-37I 34 Verona, Italy

Email: dd.gazzani@gmail.com
} 